\title{
TRANSGENDER REPRESENTATION IN BANGLADESHI FILM: AN ANALYSIS OF THE FILM COMMON GENDER
}

\author{
Md. Asaduzzaman ${ }^{1}$
}

\begin{abstract}
This research has done to know how transgender people are represented in Bangladeshi film. Research found that transgender people are highly misrepresented in film and for this misrepresentation- they have to pay to achieve their rights from society. Hence, to work for the betterment of the transgender community in Bangladesh; it is important to know their representation style in Bangladeshi film. This paper has analysed the film Common Gender based on the content analysis method and the film narratology method while the representation theory worked as its theoretical framework. This paper found the film has represented transgender people in the same way that the Bangladeshi dominant society thinks about transgender people. There are no differences between the representation style and the reality. Hence, it can be argued that Bangladeshi films are influenced by the Bangladeshi dominant culture and transgender people have to pay to achieve their rights from society.
\end{abstract}

Keywords: Bangladeshi Film, Misrepresentation, Representation, Stereotype Thought, Transgender People.

\section{Introduction}

Media text always plays a significant role to construct our identity (Gates, 2018). As a form of mass media, the film works for reflecting, constructing, and reinforcing reality. It also works to construct a culture (Paralik, 2017). The film can do it as media have the power of influence on its audiences (Gates, 2018). Therefore, a negative representation of a group in a film can be a cause of damages to the group (Reitz, 2017). Hence, accurate representation of a group, culture or society in the film is important.

\footnotetext{
1 Md. Asaduzzaman is Assistant Professor, Department of Mass Communication and Journalism, University of Dhaka, Bangladesh. Email: md.asaduzzamn90@yahoo.com

Social Science Review [The Dhaka University Studies, Part-D], Vol. 38, No. 1, June 2021 DOI: https://doi.org/10.3329/ssr.v38i1.56525
} 
Regarding this issue, Guzman (2006) said that to present any content, media are influenced by the dominating culture and beliefs. Working on transgender representation in media, Cavalcante (2018) added, media are influenced by dominating culture and stereotype thoughts to represent the transgender community and transgender people are misrepresented in the media. This misrepresentation about transgender is not only limited in a single country's boundary, but also this group is misrepresented, even in the film of India, UK, and the USA (Ahmed, 2019; Pattnaik, 2009; Jobe, 2013; "How transgender people", 2010). Though there are a few pieces of work on transgender representation style in media based on different TV programmes, reports, and news articles, but there are no works on transgender representation style in Bangladeshi film.

As film works to reflect, construct, and reinforce the reality (Paralik, 2017) and negative representation of a group in film hampers the everyday lives of the group in a society (Reitz, 2017) that is why it is important to know how the transgender people are represented in Bangladeshi film. Are the Bangladeshi films misrepresenting transgender people like the films of India, UK, and the USA or not?

This paper answers these questions. It has analysed how the transgender characters have been represented in the film Common Gender. This paper analysed the film based on qualitative data. To analyse the data, the content analysis method and the film narratology method have been applied and this paper has applied the representation theory as its theoretical framework.

The film Common Gender is the first and only one Bangladeshi film on transgender people still now that was produced especially based on transgender lives and it was released in 2012. As this film has produced especially based on transgender people that is why this film has a special influence on its audiences.

Analysing this film, this paper found; the film Common Gender has represented transgender people the same way that the Bangladeshi dominant groups think about them. It represented the stereotypical thoughts of Bangladeshi society about transgender people.

This paper has provided a brief discussion on the objectives of this research at the very beginning and then it has presented a review of the existing literature of this arena. A brief review of the film Common Gender has been provided just after 
the 'Bangladeshi society's attitude towards transgender people' part so that it would be easier to understand how the film has represented transgender people in this film and how much it relevant or irrelevant to the beliefs and practices of Bangladeshi society. Afterward, the theoretical framework and research methodology parts have been discussed, respectively. In the last part, the discussion and findings section thoroughly provide the outcome of this research. Ultimately, some conclusions have been drawn from the research findings.

\section{Research Objectives}

This paper has analysed the film Common Gender:

1. To explore the stereotypes thought and representation style of transgender people in the film Common Gender;

2. To explore the power relations among transgender people and other groups of Bangladeshi society in this film;

3. To explore the similarity or dissimilarity about transgender people between the representation of film and the reality and

4. To contribute to filling up the existing knowledge gaps in the field of this study and encourage more investigation.

\section{Research Question}

Based on the research objectives, this paper has analysed the film Common Gender to explore the main research question and several sub-questions.

\section{Main Research Question}

RQ 1: How this film has represented the transgender people in this film?

\section{Research sub-question}

RQ 2. How the Bangladeshi stereotypical thoughts about transgender people have been reflected in the film?

RQ 3. What is the relationship between Bangladeshi dominant culture and film?

RQ 4. What are the power relations among society's majority group, minority group and media? 


\section{Literature Review}

Media have a great influence on its audiences and based on it, different media effect theories have been appearing such as magic bullet theory, agenda-setting theory and uses and gratifications theory. Regarding this issue, Zain (2014) and Happer \& Philo (2014) said, the way a group of people is represented in the media; the audiences think about the group in the same way.

As a form of mass media, the film also influences its audiences. Acknowledging this thought, hooks (1996) added; the film not only reflects the culture but also constructs the culture. Supporting hooks (1996), Paralik (2017) added; the film works for reflecting, constructing, and reinforcing reality. So, it can be said that the ideal representation of a group in the film is important for the betterment of the group.

However, Guzman (2006) said, to present any content, media are influenced by the dominating culture while Dukes \& Gaither (2017) and Horton, Prince and Brown (1999) opined that the films represent minorities stereotypically. Working on transgender representation in film, Jobe (2013) said, the transgender people often get misrepresented in film. Cavalcante (2018) added, this society attempts to establish them as a prostitute, sex worker and addicted and we notice the same presentation in the film about them. Jobe (2013) also added, producer uses a transgender character to sensationalize the story and Reitz (2017) said, in the film; transgender women often cast as villains that is why the transgender women fight more to achieve their equal rights in society.

Moreover, this misrepresentation is not only limited in the boundary of a single country, but also this group is misrepresented all over the world. In America, the transgender community faces a lot of damage for negative representation in film (Jobe, 2013). A research report based on the The UK's transgender people expressed that the "transgender people are deeply dissatisfied with the way they are portrayed by the media" ("How transgender people", 2010, p.11). Banerjee (2015) also added, transgender people have been represented in Bollywood as "terrifying villains or ridiculous comic relief" (p.1).

Additionally, Cavalcante (2018) said, the media represent the transgender in the same way that we notice in our society and in our everyday life. To draw an example about transgender representation in the media, he quoted a news media, and it was- "The [news] media says trans women are supposed to be sex worker, 
and have HIV, and live in SROs (Single Room Occupancies) in a tough part of town" (Cavalcante, 2018, p. 80).

Therefore, it can be said that Hollywood, Bollywood, and British cinema all misrepresent transgender people and for this worldwide misrepresentation; transgender people are paying all over the world. The above scholars also indicate, to work for the betterment of the community in a country; it is important to know how the country's film represents transgender as it gives an overview of the society's attitude toward transgender.

However, Bangladeshi media also represented transgender people in the same way that this paper discussed above (Aldama, 2019; Stenquist, 2015; Halder, 2017; Hossen, 2012; "Discrimination starts", 2019; "Bangladesh: Transgender men", 2018). We get this scenario about the representation of transgender people in Bangladeshi media based on different reports, TV programmes and news articles, but there are no works on transgender representation style in Bangladeshi film. It happened as no films were produced based on transgender people till 2012 in Bangladesh. Though the film Common Gender was released in 2012, no work has done on this film yet.

In Bangladesh, transgender is a minority group (Stenqvist, 2015) and they are fighting to achieve their basic rights (Aldama, 2019). Scholars said, the negative representation of a group in film hampers the everyday lives of the group and it will be worse if the group belongs to a minority group (Reitz, 2017). Besides it, previous research said, Hollywood, Bollywood and British cinema all misrepresent transgender people and for this misrepresentation, they have to pay for it.

In these circumstances, to work for the betterment of the transgender people in Bangladesh; it is important to know how the Bangladeshi film represents transgender people. Besides it, this work has been able to insert new knowledge in this area about Bangladesh context and it has presented an overview of the transgender people's condition in Bangladesh and Bangladeshi society's attitude towards transgender people based on existing literature and pieces of evidence that are also important to work for the betterment of transgender people in Bangladesh. 


\section{Bangladeshi Society's Attitude towards Transgender People}

In Bangladesh, people address transgender people as hijra, and this community is one of the most marginalized and crossed minority groups in Bangladesh (Stenqvist, 2015). Like the other babies, here, the trans babies also born in a family and they grow up with their family members normally. But the problem starts gradually with the raising of their age.

After a certain period, when the family and society notice that their physical shape is not normal like others, then the society and family cannot accept them normally ("Discrimination starts in", 2019). The stigma of being a hijra starts from the family first ("Discrimination starts in", 2019). Society does not treat the family in a good way where a hijra inhabits that is why it forced hijras to seek a life with other hijras outside of the family to protect their family from further societal stigma (Stenqvist, 2015).

Besides it, mainstream Bangladeshi society refuses to develop any social relationship with transgender people. The hijras are excluded from accessing social institutions and services such as education, housing, and health care ("Bangladesh: Transgender men", 2018; Halder, 2017). Bangladeshi society also does not offer them any job that is why they have to depend on the kindness of people to survive or many of them turn to occupation within prostitution, drugs, begging and other illegal activities (Rahman, 2009).

In addition, they are also facing dominance, violence, and abuse by the people of Bangladesh. "Violations occur in forms of abduction, arbitrary arrests, detention, beatings and gang-rape by law enforcement agencies and others" (Sexual Rights Initiative, 2009, cited in Stenqvist, 2015, p. 12). They also face "molestation, both on physical and psychological levels, of people with non-heteronormative gender expressions and attributes" (Sexual Rights Initiative, 2009, cited in Stenqvist, 2015, p. 12). These all indicate that transgender people are living in a vulnerable position in Bangladesh and here, they cannot enjoy their human rights fully.

Recently, Bangladesh Government has given full recognition to the hijras by creating a special sex category on Bangladesh's national voters' list as 'hijra' (Wallen, 2019). Though it is a big achievement for transgender, they are still fighting to get recognition from society as human beings (Aldama, 2019). 


\section{The Film Common Gender}

Famous filmmaker Noman Robin's full-length feature film Common Gender ("Common gender-the film", 2015). This film was produced based on the love story of a hijra (transgender). Besides, this film is the first and only one Bangladeshi film that vividly described the lifestyle of Bangladeshi transgender people and the public perception towards transgender people. It was released in 2012 and it is one of the first films in the world movie in which two transgender people worked as lead characters and it was subsequently released in the United States (Hossen, 2012). The story of this film has been presented in the 'discussion and findings' part under the 'histoire' section of this paper.

\section{Theoretical Framework}

The representation theory has been applied in this research to understand why transgender people are represented in a specific way in the media. Besides, it is important to understand the political economy of representation which is connected to the critical approach of text analysis.

To define representation, Hall (1997, p. 1) said, "representation means using language to say something meaningful about, or to represent, the world meaningfully, to other people". Representation engages meaning and language to culture. It is a process by which meaning is produced in society and be exchanged among the members of the society (Hall, 1997). In this process, ideology and power set up the meaning of a given text (Hall, 2000).

It indicates that the dominating culture plays a significant role to construct meaning as there is the question of power. Hence, to understand and analyse how the given text works in the existing socio-economic structure, representation theory is important. Accordingly, to understand the political economy of the construction and representation of transgender people in this film; the representation theory is also important.

There are three approaches to explain how the representation of meaning through language works. They are the reflective approach, the intentional approach, and the constructionist approach ("Stuart Hall the work", 2012).

According to the reflective approach, the meaning is supposed to lie in the object, person, or idea in the world and here, language work as a mirror. In contrast, the intentional approach of representation argues that the speaker or the author 
imposes meaning on the world language (Sherpa, 2019). On the other hand, the constructionist approach states that people construct meaning through concepts and signs. We produce our own meanings to an object, person, or idea through our own language ("Stuart Hall the work”, 2012).

This paper has used the constructionist approach of representation to analyse the dialogue, language, gesture, posture, music, dance, and dress of the film through which the paper has found how the transgender people have been presented in the film Common Gender.

\section{Research Methodology}

As this research is following qualitative approach, the content analysis method has been applied to analyse data. Additionally, to analyse mass media content or text; researchers apply film narratology as a method. Rudrum (2002) said,

It scrutinises the internal relations of a narrative's component parts and dissects how these relations are constructed in practically any given aspect of the narrative text (such as plot, narration, sequence of events, and so on) (p.1).

Hence, to analyse the film; this paper also applied the method of film narratology.

However, Gérard Genette (1980) mentioned three categories or terminologies by which we can analyse media content and text. Genette (1980) argued, the concept of "narrative" has been developed based on these categories and they are recit, histoire and narration. The film Common Gender has been analysed based on these terminologies.

First, this paper has discussed the histoire (story) of the sampled film and then the recit (message). In the last part, this paper has discussed the narration (narrative strategy) of the sampled film.

\section{Discussion and Findings}

\section{Histoire}

This film has shown, like the other babies; the trans babies also born into a family and they grow up with their family members normally. But the problem starts gradually with the raising of their age. When the family and society notice, their physical shape is not normal like others, then the society and family cannot 
accept them normally and force them to live with other hijras outside of their family.

Like this way, a child named Babu (familiar as Bubli in this film) born into a family, but she cannot live with her family as her family members force her to live outside of the family with other hijras. Though her mother tries to keep her with them, her other family members do not show any attention to her appeal and the same thing happen with Shushmoy (familiar as Shusmita). In these circumstances, both Bubli and Shusmita start to live with other hijras.

As society does not offer them any job or work that is why Shusmita and Bubli both go shop to shop and collect money to survive like the other hijras. Many of them also involve with various illegal activities to survive. Like the other hijras, this society also treats Bubli and Shusmita as sexual objects. This society thinks they are here to entertain them.

However, one day, a Hindu family invited Shusmita and her group at a wedding programme for entertaining them by dancing and singing. Seeing Shusmita, a transgender youth, at the wedding programme; Shonjoy wants to make friendship with Shusmita. They spend some time talking with each other at the wedding programme and Shonjoy shares his phone number with Shusmita.

After the wedding programme, one day; Shusmita contacts Shonjoy over the phone. They start to communicate with each other over the phone regularly and it makes the friendship between them over time.

One day, Shonjoy said Shusmita over the phone that it could be much better had Shusmita been a girl. This statement changes something inside Shusmita. Shusmita starts to behave more like a girl and falls in love with Shonjoy. They start to spend their time together and share their feelings with each other.

One day, Shonjoy took Shusmita to their home, his parents obscenities Shonjoy for making friendship with a transgender and insult both. This humiliation forces Shusmita to commit suicide. After the death of Shusmita, the caretaker of a graveyard disagrees to bury Shusmita at the graveyard as Shusmita neither a male nor a female.

In the last scene, Bubli goes to her family to meet his mother, but her family members do not allow her to meet with her mother and beat her badly for coming 
to her family. After returning, Bubli also commits suicide and raises a question, how their God will treat them? Male or female? As this society treats them, neither a male nor a female and they suffer a lot not for being a male or a female that is why she raises the question.

Consequently, this film's story is like the position of Bangladeshi transgender people. It represented the same scenario that this paper mentioned about Bangladeshi transgender people in 'Bangladeshi Society's Attitude towards Transgender People' part above. Therefore, it can be said that the film Common Gender represented transgender people the same way that the Bangladeshi people or society think about transgender people. There is no difference between the film and reality.

\section{Recit}

According to the method of Gérard Genette, this part has analysed the character's dialogue, accents, gesture, posture, music, dance, and dress of the sampled film. Analysing these, this paper found, the film presented transgender people in the following ways:

\section{Transgender is a curse for their family}

Different parts of this film indicate the transgender is destroying their family's prestige by their activities. At the very beginning of this film, when the CD owner complains to Raju about Bubli's activities, then Raju (Bubli's brother) said, "there is a thing called honour even that is gone now." Regarding this issue, Bubli's father said to her mother that "whose curse, is it? We have been suffering for 22 years" and Bubli's father also prays to God saying- "oh God! Please do not bring this even upon my enemy." These conversations clearly express that transgender people are a curse to their families.

\section{Transgender is not entirely a human being}

This film indicates, Bangladeshi society does not treat them as an entire human being. They always treat them as a transgender and their expression indicates that the transgender is not human beings. In different contexts, the transgender people tried to prove them as a human being to confront different issues. Transgender asked people saying- "why people are behaving with them in this way? Are not they human beings?" In response, people said, they are human beings but 
transgender. It seems that transgender is not a human being. It also indicates, transgender people are still fighting with this society to get recognition as human beings.

\section{Transgender is not polite or civilized}

In a scene in this film, one man warned the transgender people saying that "this is a decent neighbourhood. If you can live decently then stay here, otherwise please leave this area." It indicates that they are not polite and to live with the general people they have to be polite. Besides it, in different ways, this film represented them as uncivilized. (See Appendix-1.8 for more)

\section{People hate transgender}

At the very beginning of this film, a police officer addresses transgender people saying- "if you want money just ask for it. Why do you have to touch?" Besides it, in different parts of this film, people asked them not to touch them and in response, the transgender people raise the question- "are we not humans being?" Their language and expression indicate- the people of the Bangladeshi society hate transgender people that are why they do not allow transgender people to touch them. (See Appendix 1.1 for more)

\section{Transgender is here to entertain people}

Different parts of this film indicate that transgender people have born to entertain society. Once, one Hindu family invited transgender people to a wedding programme to entertain their family by performing songs and dances. Additionally, different parts of this film showed that transgender people are entertaining people by their activities and performances. (See Appendix 1.2 for more)

\section{Narration}

This paper has analysed the narrative strategy of this film and found that the film presented the transgender people in the following ways:

\section{Transgender does not have any rights in society and family}

Analysing this film, this paper found; families severed relations with transgender as their children or siblings after a certain time. Society does not recognize their 
love, romance, and friendship with normal people. Transgender people cannot live with their family as well as in a good place that is why they have to live in a shantytown (See Appendix-1.3 for more). Society does not offer them any job or work that is why they beg or involve themselves in illegal activities to survive (See Appendix-1.4 for more).

Additionally, society treats them as transgender, neither male nor female. This treatment creates problems for them such as they cannot use a public toilet for this treatment as the public toilets are dedicated to males and females separately in Bangladesh. As transgender people neither male nor female that is why they cannot use it.

Moreover, after their death; they face the same problem for this treatment as Bangladeshi Islamic society prefers to bury male and the female in different places and there are also some different rules for male and female in Janazah prayer. As they are neither male nor female, hence it makes problems to categorize them. After the death of Shusmita, we noticed- the caretaker of the graveyard disagreed to bury Shusmita as Shusmita is neither a man nor a woman and he has never buried a transgender (See Appendix-1.5 for more). These all express the position of transgender people in society that indicates- transgender does not have any rights in society.

\section{Transgender people are sexual objects}

This research observed, society treats them as their sexual objects. In a scene when a rickshaw puller saw a transgender person, he approached, "you want to go somewhere? Come with me?" A truck driver said, "Want to go on a truck? Come with me." A young boy said, "Where are you going? Let us play." Throughout the entire film, transgender people have shown different private parts of their bodies and use different slang, sexual words, and expressions in their conversation. They tried to show their sexual attractiveness by their gesture and posture that enjoyed everyone, and people want to see transgender people in this role. This film also showed, some people touch transgender women unnecessarily just to satisfy their sexual demands and transgender women are allowing it. It all indicates society's sexist attitude toward transgender people. (See Appendix-1.6 for more) 


\section{Transgender is helpless}

While begging in a market, Bubli was talking with a shopkeeper in the following way- "oh Allah, won't you look after us? Our parents will not care for us. The government will not look after us, this man here will not either. What are we supposed to do? How will we live if we don't eat?" This conversation clearly expressed their helplessness. (See Appendix-1.7 for more)

\section{Transgender has to depend on the kindness of people to survive}

The film showed that transgender people are going door to door to survive. They are begging and acknowledging that without the support of people, they will not survive. One day Shusmita said, "We live off whatever money these people give us" (See Appendix-1.4 and 1.7 for more).

\section{Transgender is involved in illegal activities}

The entire film indicates that transgender people are involved in smuggling, hijacking, begging, snatching, prostitution, and other illegal activities (See Appendix-1.8 and 1.9 for more). One day, some Muslims said to the transgender people that "yesterday we saw you were fighting with each other, don't do this." Moreover, this film showed; snatchers once snatched Sanjoy's phone, and the transgender people recovered it from the snatchers as the transgender people have so many connections with muggers or illegal people. These scenes indicate their illegal activities.

\section{People can abuse transgender physically and verbally}

This film presented, people, family members and anyone can abuse them physically and verbally and transgender people have no options without allowing it and there is no remedy for it. Once Shabnam Mashi mentioned, "people in a market had once physically abused Shahjada Mashi." This film also presented, people and a security guard once beat Bubli badly just for using public toilets and Bubli's brother to also beat Bubli just for going to their family (See Appendix1.10 for more). Regarding this issue, one day, Shusmita told Shonjoy that "I have been grown up by tolerating insult from numerous people." 
Consequently, analysing this film; it can be said that the stereotypical thoughts of Bangladeshi society about transgender people have reflected in this film. This film represented, transgender people are excluded from family, education, job, housing, healthcare, and other basic facilities. They live depending on people's kindness. They are treated as sexual objects, and anyone can abuse them verbally and physically and they have nothing to do. They are a curse to their families. They are involved in different illegal activities, and they are not civilized. All of these are the stereotypical thoughts of Bangladeshi dominant society about transgender people and this film has presented these the same way.

Additionally, the transgender is a minority and others are the majority in Bangladesh that is why the transgender people are controlled by the other groups and the transgender people are allowing it as they have nothing to do. The media are presenting this scenario in a way that seems to us as natural and as the rule of society. Here, we notice the power relations and their effects among minorities, the majority, and the media. Therefore, supporting Hall (2000), it can be said that power sets up a meaning.

Moreover, all the data and evidence show that there is no dissimilarity between the representation of the film and reality. Therefore, supporting Guzman (2006) and Cavalcante (2018), it can be said that the media are influenced by the dominant culture.

\section{Conclusion}

To find out the transgender people's representation style in Bangladeshi film, this paper has examined the film Common Gender. After analysing this film, this paper found; this film has represented transgender people the same way that the Bangladeshi dominant society thinks about transgender people. It has represented the stereotypical thoughts of Bangladeshi society about transgender people. There is no dissimilarity between the representation of film and reality. In conclusion, it can be said that this film has misrepresented transgender people like Hollywood, Bollywood, and British films. Before concluding, it should clarify the limitations of this study. This paper has analysed only one film to reach this decision, so it is difficult to generalize this finding for all Bangladeshi films. 


\section{References}

Ahmed, A. (2019). Third gender portrayal in Bollywood: An analysis of Sadak. International Journal of Trend in Scientific Research and Development (IJTSRD), 3(3), 17-22.

Aldama, Z. (2019, July 20). In India, Bangladesh and Nepal, transgender communities exist on margins of society, waiting for change in public opinion. Post Magazine. Retrieved from https://www.scmp.com/magazines/post-magazine/long-reads/article/3019278/indiabangladesh-and-nepal-transgender

Banerjee, R. (2015, August 28). How Bollywood's representation of transgender people is downright horrifying. YKA. Retrieved from https://www.youthkiawaaz.com/2016/ 05/bollywood-transgender-representation/

Bangladesh: Transgender men fear for their safety. (2018, January 19). Human Rights Watch. Retrieved from https://www.hrw.org/news/2018/01/19/bangladesh-transgender-men-fear-theirsafety

Cavalcante, A. (2018). Struggling for ordinary: media and transgender belonging in everyday life. New York: New York University press.

Common Gender-the film to be screened at BSA today. (2015, August 28). The Independent. Retrieved from: http://www.theindependentbd.com/arcprint/details/13476/2015-08-28

Discrimination starts in the family. (2019, November 18). The Daily Star. Retrieved from https://www.thedailystar.net/city/news/discrimination-starts-the-family-1828591

Dukes, K., \& Gaither, S. (2017). Black racial stereotypes and victim blaming: Implications for media coverage and criminal proceedings in cases of police violence against racial and ethnic minorities. Journal of Social Issues. 73(4), 789-807.

Gates, R. (2018). Double negative: the black image and popular culture. Durham: Duke University Press.

Genette, G. (1980). Narrative Discourse. Oxford: Blackwell.

Guzman, I. M. (2006). Mediating Frida: Negotiating discourses of Latina/o authenticity in global media representations of ethnic identity. Critical Studies in Media Communication. 23(3), 232-251.

Halder, A. (2017, October 6). Leaving no one behind: "Hijra Lives in Bangladesh". The Daily Star. Retrieved from: https://www.thedailystar.net/star-weekend/human-rights/leaving-no-onebehind-hijra-lives-bangladesh-1471990

Hall, S. (2000). Cultural identity and cinematic representation. In Robert S. \& Roby M. (eds), Film and Theory (pp. 704-714). Oxford: Blackwell.

Hall, S. (1997). The work of representation. In Hall, S. (ed), Representation: cultural representations and signifying practices (pp.1-47). London: Sage.

Hall, S. (1992). Culture, media, language: working papers in cultural studies, 1972-79. London: Routledge.

Happer, C., \& Philo, G. (2014). The role of the media in the construction of public belief and social change. Journal of Social and Political Psychology, 1(1), 321-336.

Hooks, B. (1996). Reel to real : race, sex and class at the movies. London: Routledge.

Horton, Y., Prince, R., \& Brown, E. (1999). Portrayal of minorities in the film, media and entertainment industries. Poverty \& Prejudice: Media and Race. 
Hossen, A. (2012, July 11). Dhakar Chobi ‘common gender` niye matamai (Shindig for Dhaka's film 'Common Gender'). BBC Bangla. Retrieved from https://www.bbc.com/bengali/ news/2012/07/120711_mhcommongender

How transgender people experience the media: conclusions from research November 2009February 2010. (2010, April). Trans Media Watch. Retrieved from http://www.transmediawatch.org/Documents/How\%20Transgender\%20People\%20Experience $\% 20$ the $\% 20$ Media.pdf

Jobe, J. N. (2013). Transgender representation in the media [Honours thesis, Eastern Kentucky University]. Retrieved from https://encompass.eku.edu/cgi/ viewcontent.cgi?article $=1145 \&$ context $=$ honors_theses

Pattnaik, S. (2009). Outside the frame: representation of the Hijra in Bollywood cinema. Intersections: Gender and Sexuality in Asia and the Pacific, 22. Retrieved from http://intersections.anu.edu.au/issue22/pattnaik.htm (Accessed on June 25, 2021).

Paralik, B. (2017). Black lesbian, gay and transgender representations in films: stereotypes, power relations and gender roles, an intersectional analysis of the films Set It Off, Tangerine and Moonlight [Master's thesis, Linköping University]. Retrieved from http://liu.divaportal.org/smash/record.jsf?pid=diva2\%3A1144124\&dswid=-4398

Rahman, M. (2009, April 30). Organised crimes by hijras shoot up. The Daily Star. Retrieved from https://www.thedailystar.net/news-detail-86234

Reitz, N. (2017). The Representation of trans women in film and television. Cinesthesia. 7(1), 1-7. Retrieved from https://scholarworks.gvsu.edu/cgi/viewcontent.cgi?article=1125\&context=cine (Accessed on June 25, 2021).

Rudrum, D. (2002). Narratology. The Literary Encyclopedia. Retrieved from http://eprints.hud.ac.uk/id/eprint/2968/1/Literary_encyclopedia_topics_1252.pdf (Accessed on June 30, 2021).

Sherpa, N. (2019). A summary of representation, meaning and language by Stuart Hall. Creative Writing Nepal. Retrieved from https://www.creativewritingnepal.com/stuart-hallrepresentation-meaning-language/

Stenqvist, T. (2015). The social struggle of being HIJRA in Bangladesh - cultural aspiration between inclusion and illegitimacy [Master's thesis, Malmö University]. Retrieved from http://muep.mau.se/bitstream/handle/2043/18568/Stenqvist-T-

DP15\%20final.pdf?sequence $=2 \&$ isAllowed $=y$

Stuart Hall, "the work of representation" (8/31). (2012, September 11). Media \& Culture Theory. Retrieved from https://comrt465mitrano.wordpress.com/2012/09/11/stuart-hall-the-work-ofrepresentation-831/

Wallen, J. (2019, April 29). Transgender community in Bangladesh finally granted full voting rights. The Telegraph. Retrieved from: https://www.telegraph.co.uk/global-health/climateand-people/transgender-community-bangladesh-finally-granted-full-voting/ (Accessed on March 21, 2021).

Zain, M. (2014). Agenda setting theory. Research Gate. Retrieved from https://www.researchgate.net/ publication/321698436_Agenda_Setting_Theory 


\section{Appendices}

\section{Appendix-1.1 (People hate transgender)}

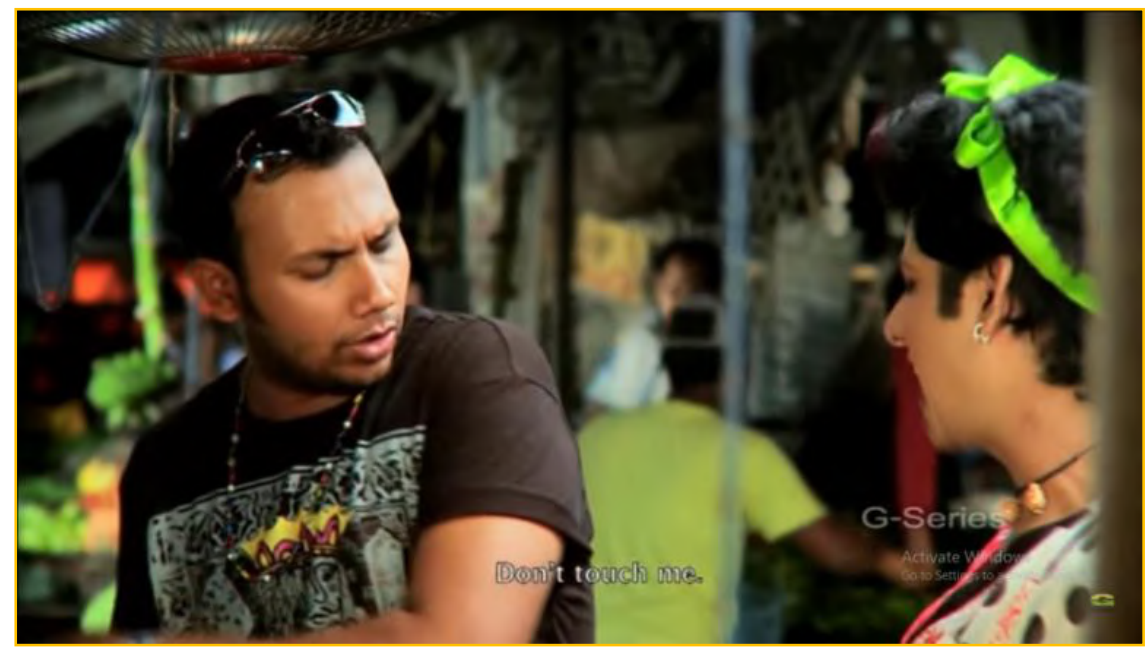

In the first picture, a man is telling a transgender woman not to touch him and in the second picture, one police officer is also telling a transgender not to touch him and subtitles on the pictures clearly showing it. The expression of the first picture also saying, he hates the transgender women.

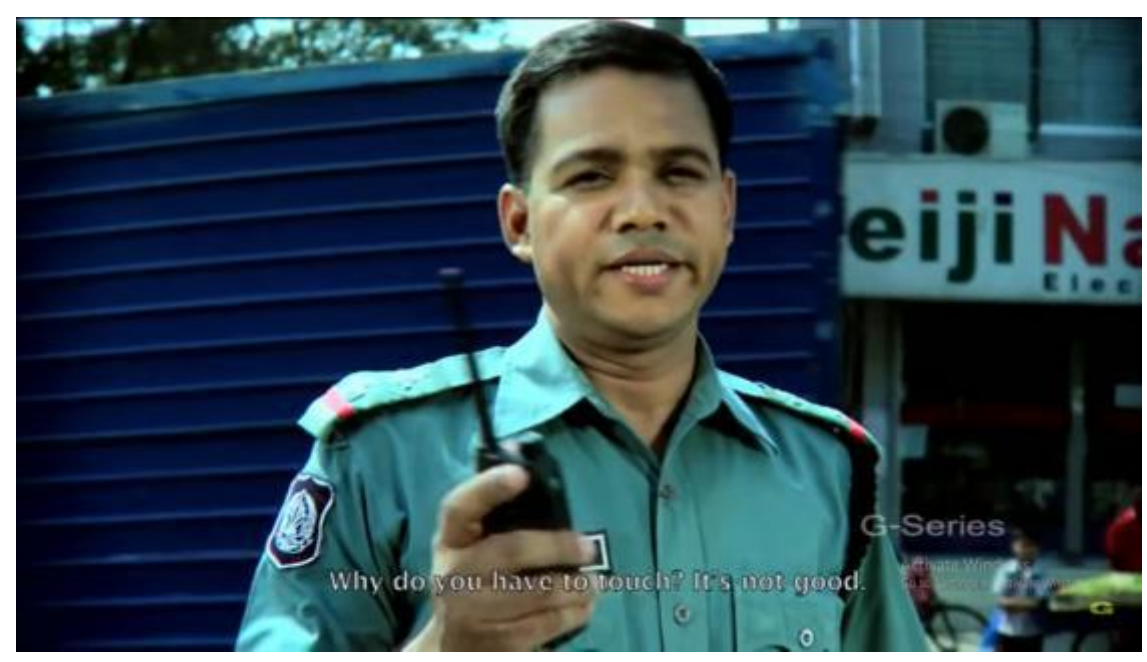


Appendix-1.2 (They are here to entertain people)

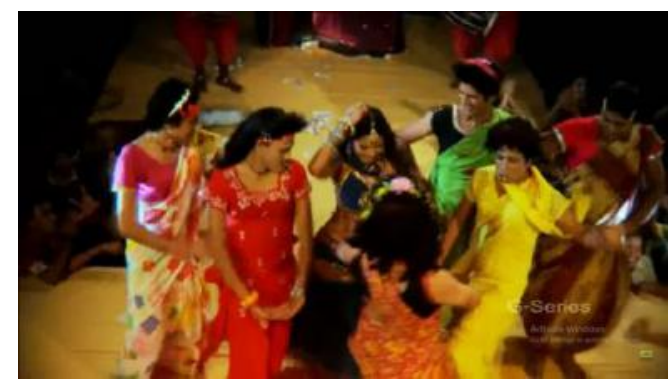

In both pictures, the transgender women are dancing and singing to entertain people.

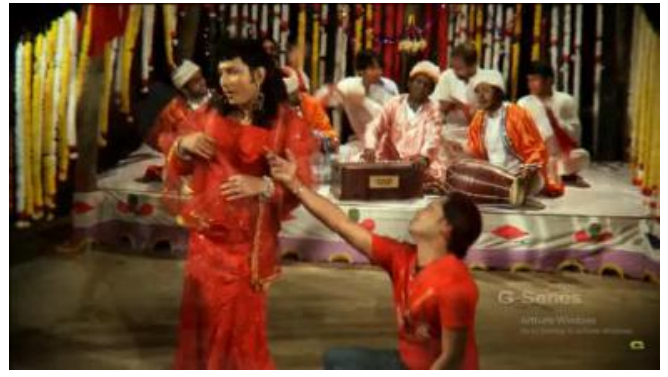

Appendix-1.3 (Live in shantytown)

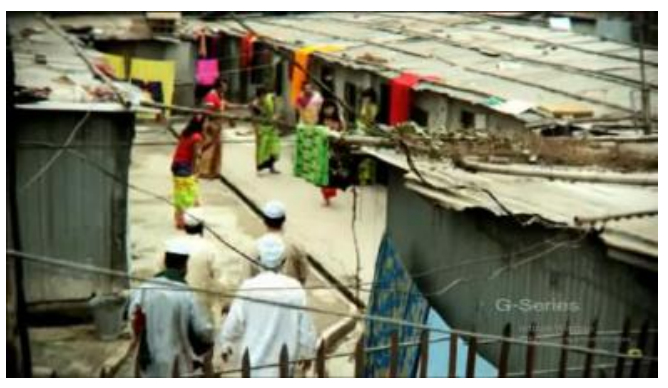

View of transgender people's living place

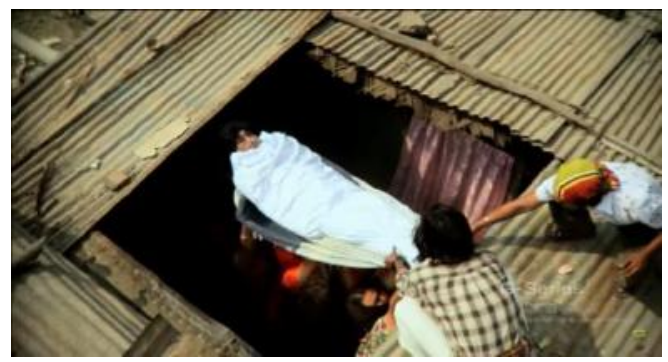




\section{Appendix-1.4 (Begging)}

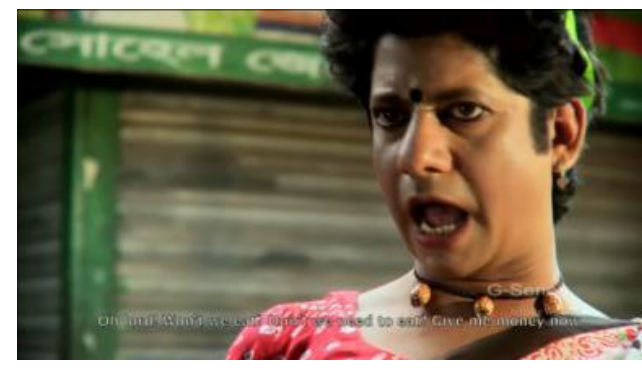

Picture-1

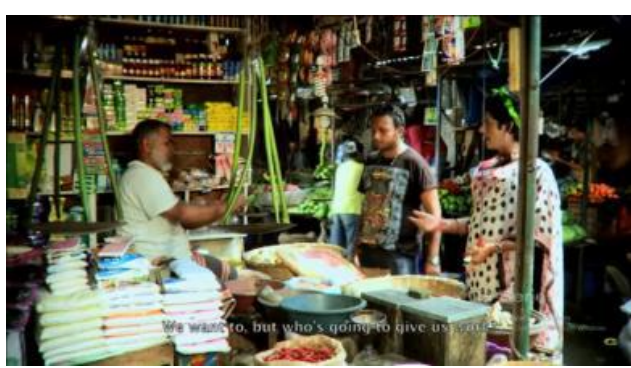

Picture-3

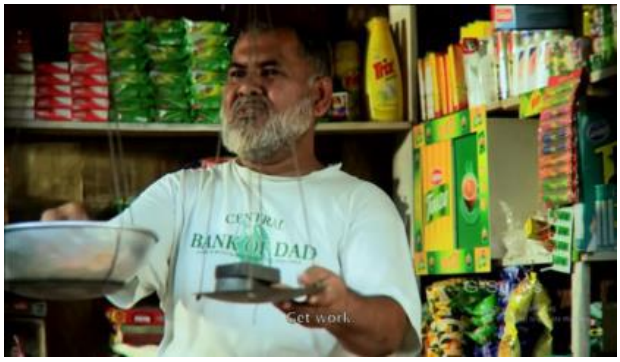

Picture-2

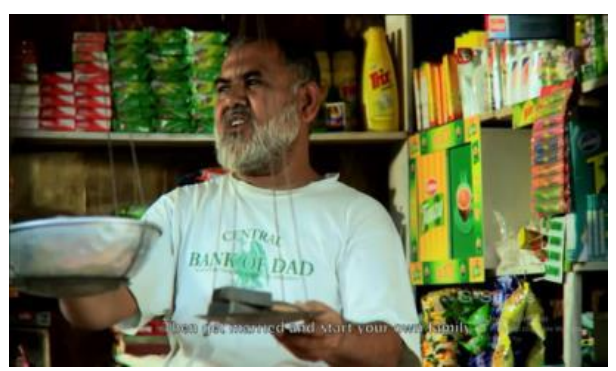

Picture-4

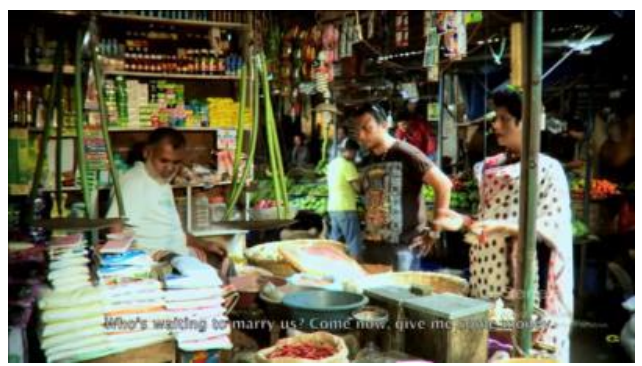

Picture-5

Bubli is begging saying- "hey mister, give me some money". In response to Bubli, the shopkeeper is asking Bubli- "what for"? Bubli replaying- "oh lord. Won't we eat? Do not we need to eat? Give me money" (Picture-1). To response, the shopkeeper advising Bubli to "get work" (Picture-2) and then Bubli answering the shopkeeper saying- "we want to but who is going to give us work" (Picture 3). Then, the shopkeeper again advising Bubli saying- "then get married and start your own family" (Picture-4). In response to shopkeeper, Bubli is saying- "who is waiting to marry us? Give me some money" (Picture-1.5) 
Appendix-1.5 (Transgender does not have the right to be buried)

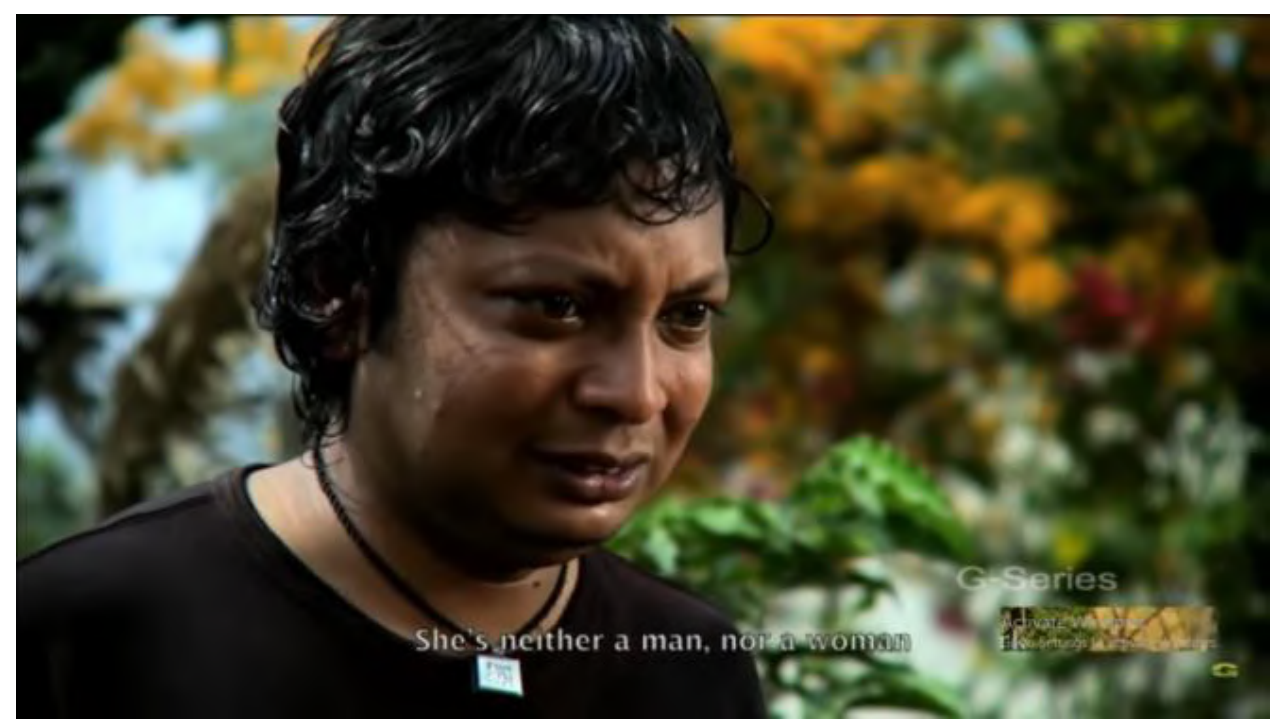

After the death of Shusmita, Tota Mia went to a graveyard to bury Shusmita, but the caretaker disagreed to burry Shushmita saying- Shusmita neither a male nor a female and he has never buried a hirja.

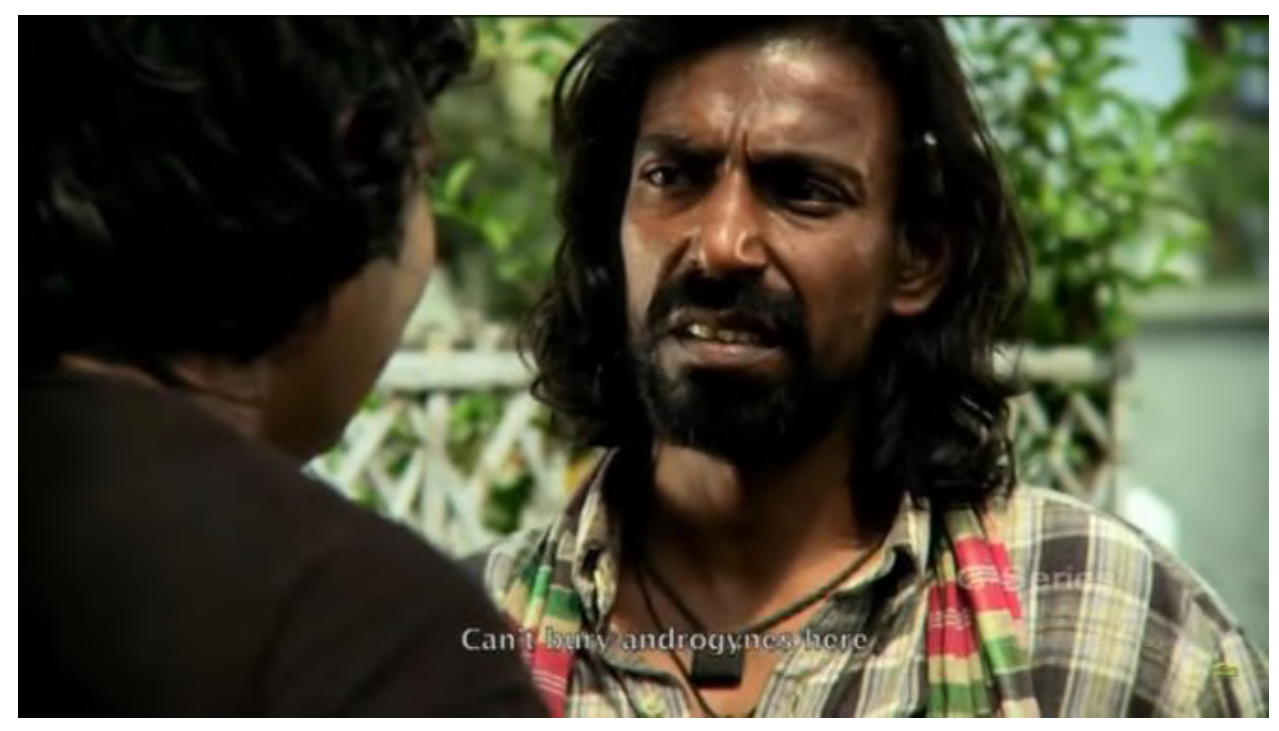


Appendix-1.6 (Transgender is sexual object)

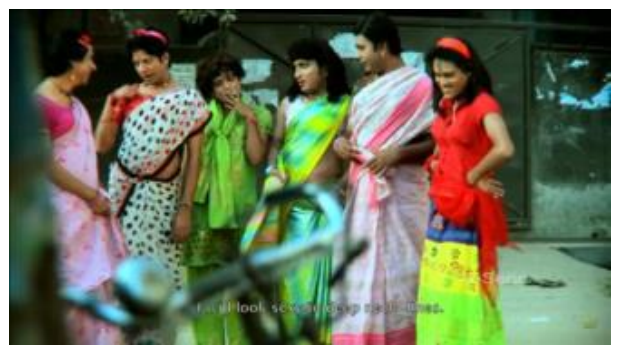

Picture-1

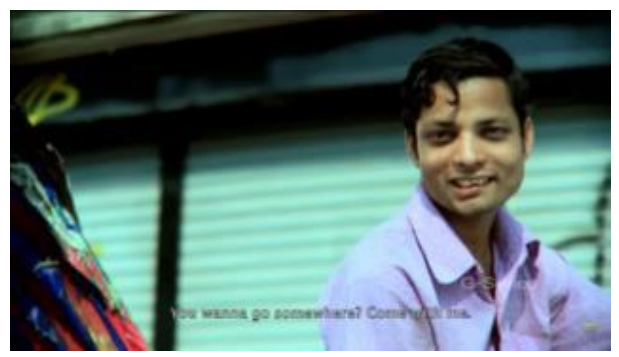

Picture-3

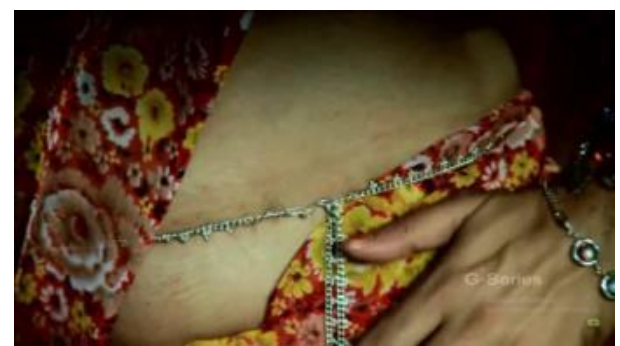

Picture-2

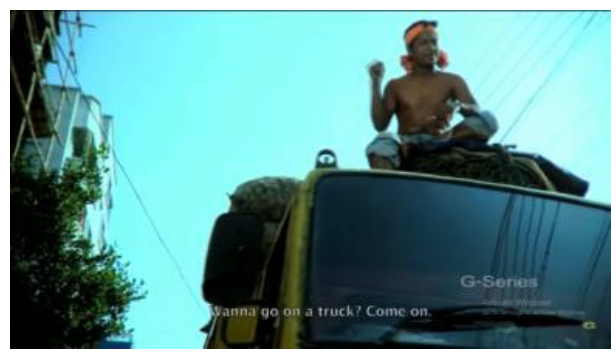

Picture-4

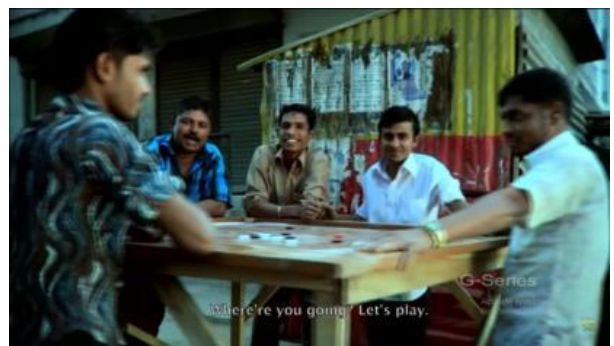

Picture-5

In Picture-1 and Picture-2, transgenders are expressing their sexual gesture. After seeing transgender, rickshaw puller says- "you want to go somewhere? Come with me"? (Picture-3) The truck driver says- "want to go on a truck? Come with me." (Picture-4) Youth says- "where are you going? Let us play". (Picture-5) 


\section{Appendix-1.7 (Transgender is helpless)}

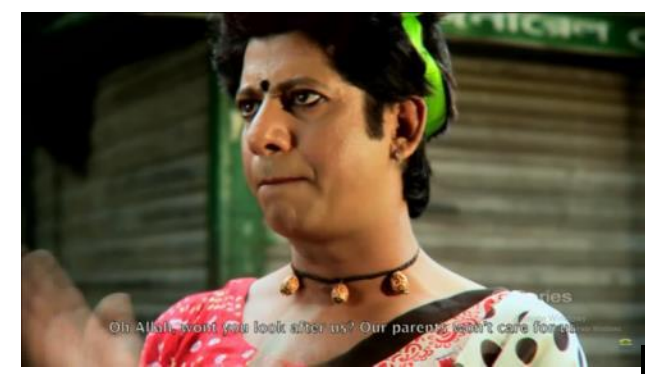

While begging, Bubli is saying- "oh Allah, won't you look after us? Our parents will not care for us (Picture-1). The government will not look after us, this man here will not either. What are we supposed to do? How will we live if we don't eat"? (Picture-2)

Picture-1

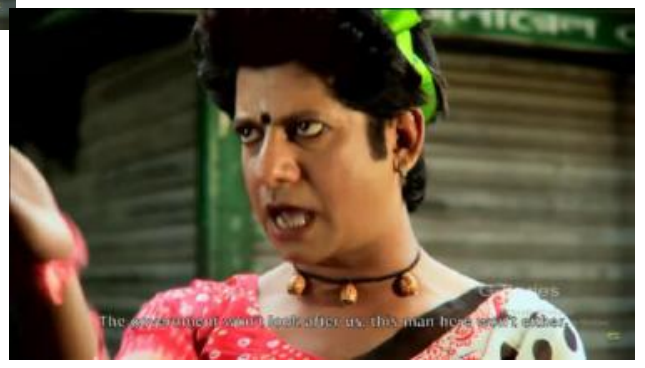

Picture-2

\section{Appendix-1.8 (Involve with illegal activities)}
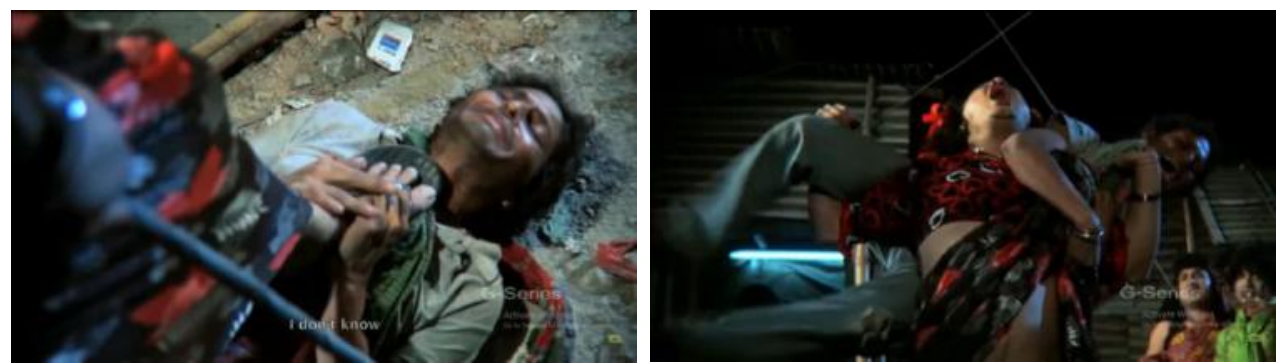

One transgender is beating a man

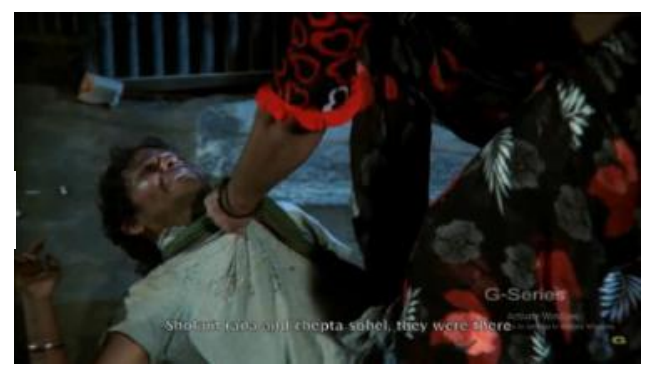


Appendix-1.9 (Drug Addicted)

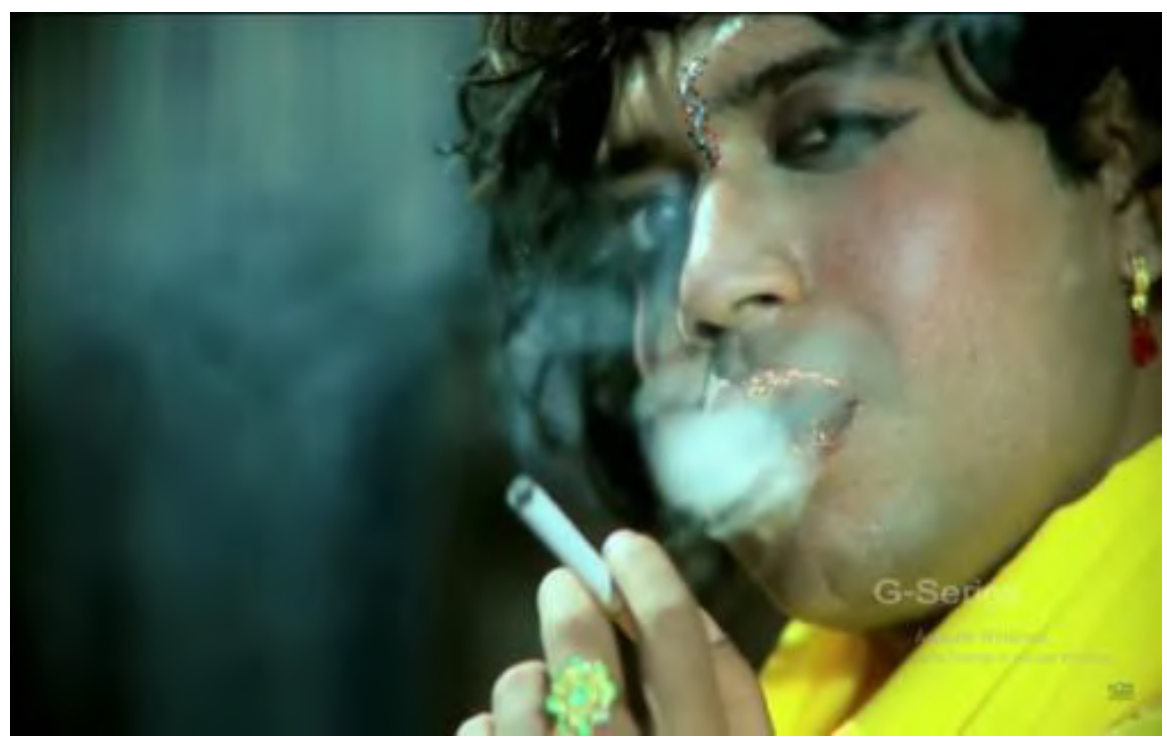

One transgender woman is smoking cigarette.

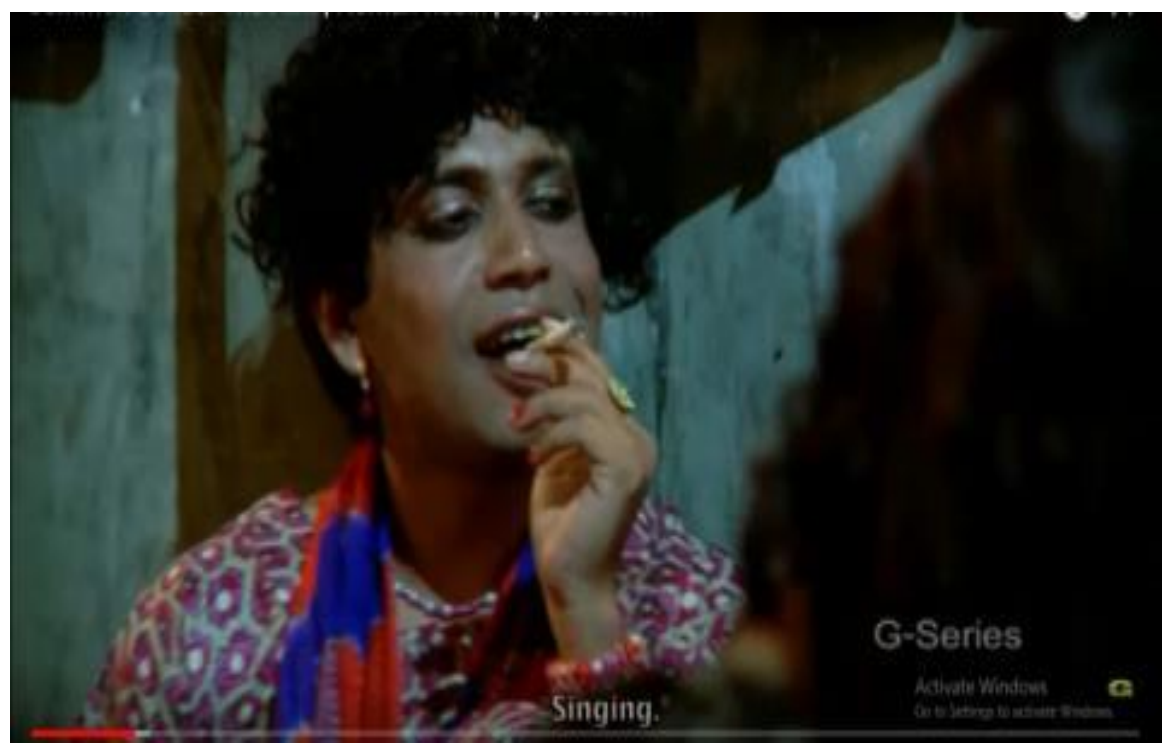


Appendix-1.10 (Anyone can beat them)
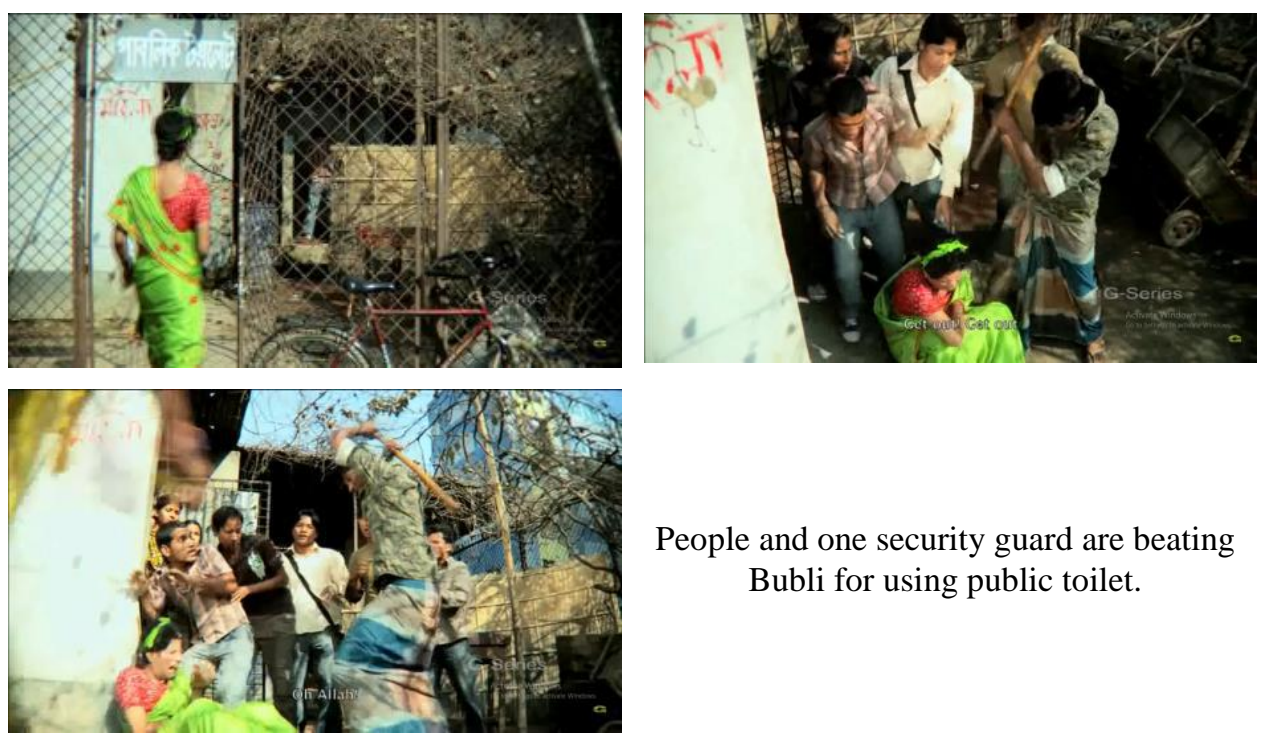

People and one security guard are beating Bubli for using public toilet.
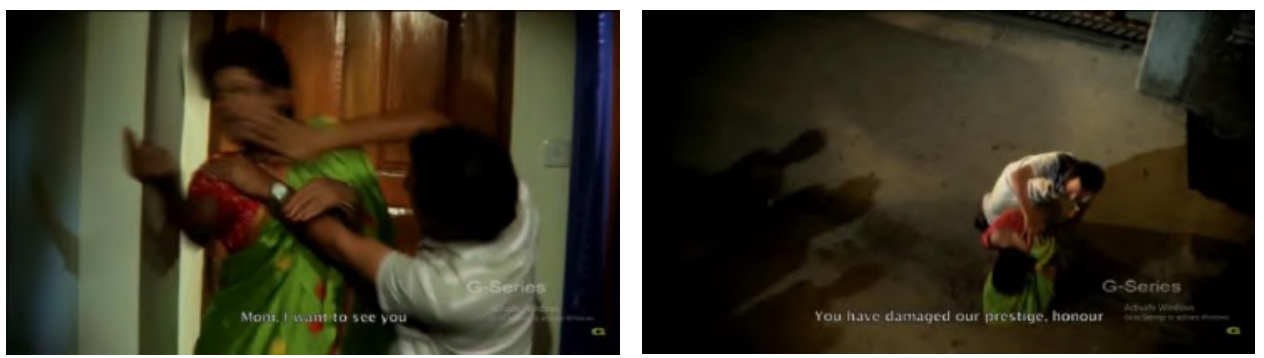

Raju (Bubli's brother) is Beating Bubli for coming to her family. 